\title{
Vaice Alarm System in Emergency Evacuation
}

\author{
Huiyang ${ }^{i^{1,2}}$ Xianghong Sun ${ }^{1}$, and Kan Zhang ${ }^{1}$ \\ ${ }^{1}$ Institute of psychology, Chinese Academy of Sciences \\ 100101 Beijing, P.R. China \\ ${ }^{2}$ Graduate School of Chinese Academy of Sciences \\ 100049 Beijing, P.R. China \\ \{lihy, sunxh, zhangk\} @psych.ac.cn
}

\begin{abstract}
Under emergency situations such as large fires, floods, hazardousmaterials, etc., incident commander have to manage an evacuation in help of alarm systems (audible or/and visual notification). This article reviewed selected literature relevant to ergonomics of alarm systems (esp. voice alarm system) in emergency evacuation, and occupants' response behavior to the voice alarm. The literature cited is of world-wide origin, and is mainly from China, Canada and U.S.. At the end of the article, future directions in the research area are recommended.
\end{abstract}

Keywords: voice alarm, alarm system, emergency evacuation.

\section{Introduction}

There are a variety of emergency situations that could justify an incident commander (IC) having to order an evacuation. The scenarios include large fires, floods, tornadoes and blizzards; hazardous-materials incidents (including biological, chemical, explosive, and radiological events); and civil disturbances, to name a few. Perhaps one of the rarest and most challenging elements of a major incident is managing the evacuation of a populated area. This is especially true when the affected area is a public one which has a large crowd of occupants with different backgrounds (e.g. age, gender, experience of evacuation training, common or handicapped).

Studies on human behavior in evacuation are mainly included in those investigating human behavior in fire. Researchers in safety engineering, ergonomics and psycho-logy began studying it as early as 1900 . John L. Bryan defined the three periods of the study area of research on human behavior in fire: (1) The "Prerecognition Years" period which was arbitrarily selected as the period from the evacuation studies of the early 1900s to the 1970s; (2) The "Productive Years" was selected to include the 1970s and the 1980s; (3) The "Performance Code Incentive Years" were identified as the 1990s into the 2000s [1].

The main methods in those researches include: interview, questionnaire [2, 3], analyzing videotapes $[4,5]$, observation $[6,7]$, experiments $[8,9]$, etc.. Issues in this study area embrace: evacuation time [5], panic behavior [10], pre-evacuation behavior, behavior differences between occupants of various ages, gender, roles, evacuating experiences and relative training [5], occupants' response to the fire alarm or public 
address system [4, 6-9, 11, 27-29], etc.. The results and conclusions of the studies gave valuable recommendation to the IC who manage the evacuation and provided quantitive and precise parameter value references to simulation of evacuation process.

Under emergency situations, environmental factors are featured in smoke, power cut, crowd, noise, etc. and occupants in a building or a location are very likely to be panic and irrational. Studies and observation found that, in order to deliver the information fast and accurately, and make the evacuation efficient and safe, the IC should use speech signals as the alarm and instructing signal instead of using bell alarm only $[11,30]$. There are some studies on speech signals and voice alarm system [12-13].

This article reviewed selected literature relevant to alarm systems (esp. voice alarm system) in emergency evacuation, and occupants' response behavior to the voice alarm. The literature cited is of world-wide origin, and is mainly from China [12-14], Canada [3-5] and U.S. [2].

\section{Alarm Systems in Emergency Evacuation}

During an evacuation, the purpose of the alarm system is to encourage the occupants to evacuate correctly and as quickly as possible. The amount of information that the system can impart relies on the style of alarm used and the occupant's interpretation of the alarm itself.

The effectiveness of alarm systems is fundamental to the success of an evacuation. An effective alarm system may not only reduce the time it takes for an individual to react to the emergency, but might initialize a predetermined chain of events which leads to the safe evacuation as well. The factors involved in the alarm system which effects this procedure can be summarized as: (1) The clarity of the warning; (2) The believability of the alarm [15].

The clarity of an alarm system concerns the information that the system provides to the population, and whether it clearly indicates the occurrence of an emergency incident; i.e., it is possible for the occupant population to determine the enclosure alarm from other adjacent alarm systems [16]. The level of effectiveness of alarm systems and occupants' understanding might be improved through the introduction of an IFWS (information warning system) alarm system, which includes a graphical/aural explanation of the event [16-20], or through public address systems and pre-recorded messages [21].

The sound of a voice-even a recorded voice-giving directions is considered to convey more authority than a simple bell. However, in using such systems operators must ensure that correct message is broadcast. The importance of this was tragically demonstrated in the Dusseldorf airport fire where incorrect messages were broadcast which directed occupants to the seat of the fire rather than to safety [21].

In addition to the clarity of information supplied, the clarity of the alarm system is also important to the reception of the alarm signal. This can be affected, especially in traditional bell alarms, by the location and power of the alarm signal. Members of the population who do not clearly receive alarm information may misinterpret or ignore the message [22].

The believability of the alarm is dependent on the frequency with which the system is tested on the enclosure population, the frequency of malfunctions, and the frequency 
of false alarms, i.e. the accuracy of the alarms [16]. The frequency of these events significantly effects the manner in which occupants respond to alarm signals [23].

Another factor that has significant influence on the success of evacuation is the level of education in the expected actions and responses to the activity of the alarm. So it seems to go along with the effectiveness of the alarm system. The interpretation and reaction of occupants to the alarm might be improved by implementing modern developments and by using a combination of audible and visual notification instead of using a single one (either audible or visual). It will increase occupant response as well as improve the system to react intelligently to the surrounding conditions.

\section{Voice Alarm System}

Generally speaking, in conventional human-machine/computer systems, the human operator's auditory channel has been primarily used for transmitting verbal communication from other operators (e.g., messages to the pilot from air traffic control) and for presenting auditory warning signals (tones, horns, buzzers, etc.). In the recent ten years, however, rapid advances in microcomputer technology have produced highly efficient speech-synthesis units generating, for example, telephone menus or simple feedback to users of computer or other systems [24].

Alarms composed of synthetic voice or recorded voice message provide one answer to the problems of discriminability and confusion. Unlike "symbolic" sounds, the hearer does not need to depend on an arbitrary learned connection to associated sound with meaning. The loud sounds "Engine fire!" in the cockpit or "There is fire on the $3^{\text {rd }}$ floor!" in a building mean exactly what they seem to mean. Voice alarms are employed in several circumstances. But voice alarms themselves have limitations that must be considered. First, they are likely to be more confusable with (and less discriminable from) a background of other voice communications, such as bell alarm sounds, the task-related communications of dealing with the emergency, or concurrent voice alarms. Second, unless care is taken, they may be more susceptible to frequency-specific masking noise. Third, care must be taken if the meaning of such alarms is to be interpreted by listeners who are less familiar with the language of the voice in a bilingual or even multilingual environment. There is an example of the limitation of voice alarm in 1977. A tragic event occurred at the Tenerife airport in the Canary Islands: A KLM Royal Dutch air lines 747 jumbo jet, accelerating for takeoff, crashed into a Parn American 747 taxiing on the same runway. Although poor visibility was partially responsible for the disaster, the major responsibility lay with the confusion between the KLM pilot and air traffic control regarding whether clearance had been granted for takeoff. An alternative method to solve the problems might be using a redundant system that combines the alerting, distinctive features of the (nonspeech) alarm sound with the more informative features of synthetic voice. Redundancy gain is a fundamental principle of human performance that can be usefully employed [25].

Voice alarm systems are also used in fire alarm and evacuation instruction systems. One of the first evaluations of the design criteria for a voice alarm system was established by McCormick as early as 1964. The design criteria consisted of "audible", "quickacting", "alerting", "discriminable", "informative", "nonmasking", "nondistracting", and 
"nondamaging" [26]. One of the early listings of the characteristics of a voice alarm system was developed at the International Conference on Fire Safety in High-Rise Buildings in 1971. These characteristics consisted of "can give precise instruction under varying emergency conditions", "vary for different zones of the building", can capture attention of the people and alert them to emergencies at hand by preconditioning", "prerecorded voice announcements can be used automatically to respond to manual or automatic fire alarms", etc. [6]. One of the first "vocal alarm system" was designed by Keating and Luftus in the Seattle Federal Building in 1974. The alerting tone consisted of a $1000 \mathrm{~Hz}$, pure sine wave tone, the voice qualities of the communicator were varied with a female voice to initiate the announcement and a male voice to provide the emergency information. The wording of the messages provided three essential contents: (1) Tell the occupants exactly what has happened; (2) tell the occupants what they are to do; (3) tell the occupants why they should do it [26].

Researches on voice alarm signal/systems design have been taken. Liang Zhang et al. investigated the effect of speech rate and tune on intelligibility of fire information words and sentences under the conditions with different levels of noise. It is found that the types of signals and noise levels affect the intelligibility significantly, e.g. the appropriate tune for fire information display interface is mezzo-soprano, the appropriate voice rate is 5 characters per second for words display, 7 characters per second for usual sentences and 6 characters per second for the sentences with numbers [12]. Tong Zhang et al. studied synthesized speech applied to warn operators of danger or failure in special working environment. The study used speech intelligi-bility test and subjective rating method, and the results showed that the speech rate for voice warnings should be with in the limit of 0.20 second/word and $0.30 \mathrm{~second} /$ word, and the optimal speech rate $\mathrm{w}$ as $0.25 \mathrm{~second} /$ word [13].

The researches above, although conclude in quantitive results, have limitations in giving advice to the design of alarm system and speech signal design for fire or evacuation alarm and instruction system. To improve voice alarm systems design, researches specifically on them are needed.

\section{Studies and Observations on Occupants' Response to Voice Alarm}

There have been both experimental and observational studies involving practice evacuations and fire incidents. These studies have involved both systems using simple signals and voice notification systems over the past thirty years.

Keating and Loftus [6] conducted two practice evacuations involving 205 participants in Seattle Federal Building in Seattle. The report indicated some general observation of the relocating occupants in response to the voice announcements: 'Personnel unhesitatingly went to the stairwells to evacuate, no one attempted to use the captured elevators, nor was there any pushing, running, or other panicky behavior observed.' Lathrop [7] has reported on a voice alarm system involved in a fire incident in the South Tower of World Trade Center, New York. It should be noted that the validity of any announcement will be questioned by occupants if the announcement is in conflict with direct physical awareness cues. Pigott has described an experiment study in a basement conference room in an office building with two randomly selected adults 
groups. The results showed that participants' response to alarm bell are significantly influenced by the voice announcement [8]. Kimura M. Sime J. D. also revealed the effect of authoritative voice instruction through observing college students evacuating from a theatre [9]. Participants who received voice instruction would start to evacuate sooner and take the correct exit. Proulx and Sime conducted 5 evacuations in the Monument underground transit station. Five different kinds of alarm and instruction information (bell only; staff only; public address system telling what to do (PA); staff and PA telling what to do; PA telling what happened, what to do and why) were used respectively in the 5 evacuations. Results showed that the more information the participants got and the more definite the information is, the less the evacuation time is. It also indicated that voice alarm system are most effective in providing comprehensive and intelligible information [27]. Proulx studied practice evacuations in four apartment buildings, one evacuation in each building which has alarm/notification systems consisted of bells. The results indicated the time to initiate the evacuation varied from 30 seconds to 24 minutes, with a mean time of 2.5 minutes [28]. Proulx studied the fire in a high-rise apartment building in Ottawa, Canada, 1997 [29]. It is found that the occupants placed considerable trust in the information received over the voice communication system, for the 83 percent of the respondents who attempted evacuation as a result of evacuation instructions given over this system.

\section{Summary and Future Directions}

Speech signals and voice alarm systems are more and more implemented in humancomputer/machine interfaces and alarm systems. On one hand, rapid advances in microcomputer technology have produced highly efficient speech-synthesis units generating in the recent years. On the other hand, voice alarm systems play an important role in fire alarm and since the first "vocal alarm system" was designed in the Seattle Federal Building in 1974. Previous work has shown that the voice alarm system is effective in facilitating the evacuation by providing information about what happens and what to do [4-9, 11, 27-29]. Studies on both voice alarm and human behavior under emergency conditions with the alarm have been taken. However, there are some limitations that must be considered.

1. In most of the practice evacuations or fire incidents, alarm bell and voice communication are used concurrently. So we can not tell effects of the different signals or communications respectively. Although most of the studies found that voice alarm was better than alarm bell, the effect of different kinds of voice notifications were not clearly described.

2. The previous studies did not investigate differences of human response to voice alarm with different physical references, such as tune, rate, type of voice, content, length of sentences, etc.. So the results of the researches can not provide good reference to the design of voice alarm system.

3. In practice evacuation, noise, smoke and other environmental features under real emergencies are not taken into account, so that the external validity of the results and conclusions is poor. 
4. There is a lack of variable (independent variable) control in observations and interview or questionnaire. Experimental method consists of deliberately producing a change in one or more causal or independent variables and measuring the effect of that change on one or more dependent variables. More experimental studies are needed in order to find causal relationships between the voice alarm and occupants' behavior.

5. There is no sound explanation of why voice notification and instruction are effective.

From the discussion above, we can see some future directions in the research areas of human behavior in evacuation, occupants' response to voice alarm systems and ergonomics of voice alarm system design. First, to provide accurate referenced data for improving an emergency action plan or a simulation system, we need quantitive data of human behavior and response to the voice alarm signals in emergency evacuation. Experimental method should be implemented. Second, scientific research is also needed to compare the effectiveness of the human behavioral response of various populations to audible emergency evacuation signal as compared with voice alarm systems and other existing audible signaling systems. Third, in experiments or practice evacuations, effects of physical parameters of voice alarm on human behavior (e.g. response to the alarm, evacuation time) might be investigated. Fourth, features in real emergencies (esp. noise) should be simulated in experiment or practice evacuation. Fifth, multiple methods, including questionnaire, interview, observation, videotape analyzing and experiment, might be combined. Experiment is good at control. Observation and videotape analyzing deals with first-hand resources. Deep interview can help to find reasons of human behavior and more about psychological aspects.

In sum, research on voice alarm system in emergency evacuation is a mutidiscipline area which began ever since 1970s. Various methods have been implemented and valuable results have been concluded. In the future, combination of multiple methods, and usage of new technologies will allow more quantitive, accurate and meaningful results which can provide references to voice alarm system design and give recommendation to evacuation plan and management.

\section{References}

1. John, L., Bryan, A.: Selected Historical Review of Human Behavior in Fire. Fire Protection Engineering, Fall, 16 (2002)

2. Fahy, R.F., Proulx, G.: Human Behavior in the World Trade Center Evacuation. International Association for Fire Safety Science. Fire Safety Science. In: Hasemi, Y. (ed.) Proceedings of the Fifth International Symposium, March 3-7, 1997, Melbourne, Australia, Intl, pp. 713-724. Assoc. for Fire Safety Science, Boston, MA (1997)

3. Proulx, G., Sime, J.D.: To Prevent Panic in an Underground Emergency: Why Not Tell People the Truth? In: Fire Safety Science-Proceedings of The Third International Symposium, pp. 843-852. Elsevier, London (1991)

4. Proulx, G., Laroche, C., Latour, J.C.: Audibility problems with fire alarms in apartment buildings. Proceedings of the Human Factors and Ergonomics Society 39th Annual Meeting, vol. 2, pp. 989-993. San Diego, Ca (October 9-13, 1995) 
5. Proulx, G.: Evacuation Time and Movement in Apartment Buildings. Fire. Safety Journal 24, 229-246 (1995)

6. Keating, J.P., Loftus, E.F.: People Care in Fire Emergencies- Psychological Aspects. Boston: Society of Fire Protection Engineers, Technical Report, 75-4 (1975)

7. Lathrop, J.K.: Two Fires Demonstrate Evacuation Problems in High-Rise Buildings. Fire. Journal 70, 65-70 (1976)

8. Pigott, B.B.: An Administrator's View of Human Behavioural Research from 1975 to 1995. In: Human Behaviour in Fire: Proceedings of The First International Symposium. Fire Sert Centre, University of Ulster, pp. 31-38 (1998)

9. Kimura, M., Sime, J.D.: Exit Choice Behavior During the Evacuation of Two Lecture Theatres. In: Fire Safety Science-Proceedings of The Second International Symposium, pp. 541-550. Hemisphere Publishing Corp, Washington (1989)

10. Mawson, A.R.: Understanding Mass Panic and Other Collective Responses to Threat and Disaster. Psychiatry 68(2), 95-113 (2005)

11. Proulx, G.: Response to Fire Alarms. Fire Protection Engineering http://www.fpemag.com/ articles/article.asp?i=267

12. Zhang, L., Sun, X., Zhang, K.: A Research of Speech Signal on Fire Information Display Interface. China Safety Science Journal 16(4), 13-18 (2006)

13. Zhang, T., Zheng, X., Zhu, Z., Jin, W.: A Study on Speech Rate of Voice Warnings. Chinese Journal of Applied Psychology 3(1), 34-39 (1997)

14. Yan, W., Chen, B., Zhong, M.: Research for Different Floors Impacting on College Students' Dispersing Psychology and Actions in the Situation of Fire Disaster. ournal of Safety Science and Technology (Chinese) 1(4), 32-37 (2005)

15. DeCicco, P.R.: Evacuation from Fires, pp. 49-50. Baywood Publishing Company, Amityvile, New York (2002)

16. Tong, D., Canter, D.: The Decision to Evacuate: A Study of the Motivations which Contribute to Evacuations in the Event of a Fire. Fire. Safety Journal 9, 257-265 (1985)

17. Tong, D., Canter, D.: Informative Warnings: In Situ Evacuation of Fire Alarms. Fire. Safety Journal 9, 267-279 (1985)

18. Bellamy, L.J.: Experimental Programme to Investigate Information Warning Characteristics for Motivating Fast Evacuations, Building Research Establishment, Borehamwood, UK (1990)

19. Bellamy, L.J., Geyer, T.A.W., Max-Lino, R., Harrison, P.I., Bahrami, Z., Modha, B.: An Evaluation of the Effectiveness of the Components of informative Fire Warning Systems, Safety in The Built Environment. In: Sime, J. (ed.) SPON, pp. 36-47 (1988)

20. Pigott, B.B.: Fire Detection and Human Behaviour. In: Wakamatsu, T., Hasemi, Y., Seizawa, A., Seeger, P., Pagni, P., Grant, C. (eds.) Proceedings of the Second International Symposium on Fire Safety Science, pp. 573-581 (1989)

21. Klein, R.A.: The Dusseldorf Airport Fire. Fire. Engineers Journal 18-23 (1996)

22. Proulx, G.: Evacuation Times and Movement Times in Apartment Buildings. Fire. Safety Journal 24, 229-246 (1995)

23. Reisser-Weston, E.: Simulating Human Behaviour in Emergency Situations. In: RINA, International Conference of Escape, Fire and Rescue (November 19-20, 1996)

24. Wickens, C.D.: Engineering Psychology and Human Performance, 2nd edn. Harper Collins Publishers, New York (1992)

25. Wickens, C.D., Lee, J., et al.: An Introduction to Human Factors Engineering, pp. 100 102. Prentice Hall, London (2004)

26. Bryan, J.L.: Psychological Variables that May Affect Fire Alarm Design. Fire Protection Engineering 11(Summer 2001) 
27. Proulx, G., Sime, J.D.: To Prevent Panic in an Underground Emergency: Why Not Tell People the Truth? In: Fire Safety Science-Proceedings of The Third International Symposium, pp. 843-852. Elsevier, London (1991)

28. Proulx, G.: The Time Delay to Start Evacuating Upon Hearing a fire Alarm. In: Proceedings of The Human Factors and Ergonomics Society. Nshville, pp. 811-815 (1994)

29. Proulx, G.: The Impact of Voice Communication Messages during a Residential High-Rise Fire. In: Human Behaviour in Fire: Proceedings of The First International Symposium. Fire Sert Centre, University of Ulster, pp. 265-274 (1998)

30. Canter, D., Breaux, J., Sime, J.: Domestic, Multiple Occupancy, and Hospital Fires. In: Canter, D. (ed.) Fires and Human Behaviour, 2nd edn. John Wiley \& Sons, New York (1990) 